\title{
A Framework for Understanding On-farm Environmental Degradation and Constraints to the Adoption of Soil Conservation Measures: Case Studies from Highland Tanzania and Thailand
}

\author{
SAMANTHA JONES * \\ University College Chichester, Bognor Regis, West Sussex, UK
}

\begin{abstract}
Summary. - This article presents a simple but valuable framework that helps to generate a clear understanding of the social causes of environmental degradation and factors that affect land user decision-making in soil conservation. It is grounded in structuration theory and resonates with recent ideas encompassed by the "sustainable livelihoods" approach. The framework is illustrated with reference to two case studies in mountainous areas where officials have, for some time, expressed a considerable degree of concern about degradation. The first is from the Uluguru Mountains of central-eastern Tanzania and the second is from the Chiang Dao District of the Northern Highlands of Thailand. The framework helps to reveal the diverse factors contributing to a lack of investment in conservation measures in these two places, in a comprehensive but nondeterministic and culturally-specific way.

(c) 2002 Elsevier Science Ltd. All rights reserved.
\end{abstract}

Key words - environmental degradation, soil conservation, structuration theory, highlands, Thailand, Tanzania

\section{INTRODUCTION}

Studies that attempt to explain the causes of land degradation are often excessively deterministic or tend to present a "shopping list" of causes (Barraclough \& Ghimire, 1996; Scoones, 1997; Whitesell, 1994). In the former case, the causes of environmental degradation tend to be viewed from a particular lens or theoretical perspective, such as neo-Malthusianism or neoMarxism. Such studies tend to present only a partial picture, as specific data are collected often in an attempt to substantiate or refute the perspective to the exclusion of other potentially relevant data or perspectives (Jones, 1999). In the latter case, studies lack explanatory value as they fail to identify the specific links and mechanisms between social variables and land degradation. In terms of soil conservation, implicitly, studies that explore the social causes of land degradation are trying to understand the reasons people do not invest to maintain land productivity. When a particular technology is being promoted, this may be investigated in a more explicit way though adoption studies. Yet these studies are plagued with similar problems. Mbaga-Smgalawe and Folmer (2000) note that despite considerable effort, there is still very little known about the adoption of soil conservation measures and most adoption models, particularly those underpinned by economic thinking, have not been very successful in explaining farmer behavior.

Structuration theory, developed by Anthony Giddens, and operationalized in development research through the actor-oriented approach (Long, 1992) is a sociological framework that may be valuably applied to help overcome these problems encountered in land degradation and soil conservation research. In taking the level of analysis as the "situated contexts"

\footnotetext{
* Final revision accepted: 12 April 2002.
} 
and everyday lives of actors and exploring the "interplay and mutual determination of "internal' and 'external' factors and relationships" (Long, 1992, p. 20), the actor-oriented approach enables the explanation of differential responses to similar structural circumstances and avoids the excessive determinism that plagues social explanation. In so doing it may be better used to understand peoples' interaction with promoted technology and, with respect to the study of land degradation, enables us to attribute a wide range of potential causes from local cultural variables, to more abstract structural influences on people's actions. Furthermore, by placing emphasis on understanding processes in particular places, it helps reveal how "factors become causes," that is, the mechanisms underlying change.

\section{THE FRAMEWORK}

The specific framework developed here is utilized in conjunction with the concept of limiting factors used by ecologists, because, as Whitesell suggests that

in the effort to derive a theory of environmental degradation and conservation with at least minimal predictive capabilities, the construction of a similar theory of limiting factors within political ecology may allow us to explain how "factors become causes" (1994, p. 4).

Listed below are the four broad variables that affect conservation decision-making and can be used to identify the different circumstances in which a certain factor or synergistic interaction of a few factors takes precedence over all others in determining outcomes (Whitesell, 1994), that is, detrimental action that causes degradation. Thus decision-makers will maintain and improve the land or adopt introduced practices ${ }^{1}$ if the following criteria are fulfilled:

(a) They have a perception of a problem of degradation: In order for farmers to want to protect the soil, they need to regard the environment to be under threat, or believe that the land may be improved by a particular practice. Interpretations of environmental change are culturally constructed and need to be thoroughly appreciated for a sound understanding of farmer behavior. Indigenous views might seem quite alien to Western scientific observers (see, for example, the Burungee "land cosmology" described by Ostberg, 1991). (b) They hold the knowledge or understanding of techniques to remedy the problem: Boserup (1965, p. 22) writes "[I]t has no doubt happened in many cases that a population, faced with a critically increasing density was without knowledge of any types of fertilization techniques. They might shorten the period of fallow without any other changes in methods. This constellation would typically lead to a decline in crop yields and sometimes to an exhaustion of land resources." Often though, soil and water conservation is the principle underlying indigenous farming methods (Pawluk, Sandor, \& Tabor, 1992) but nonindigenous observers may not "see" indigenous techniques. Soil conservation knowledge is likely to be partial, fragmented and socially differentiated (see Scoones \& Thompson, 1994) and include reworked introduced techniques (see Long \& van der Ploeg, 1994). In terms of introduced technologies, if they have been poorly explained then knowledge can be said to be a limiting factor.

(c) They have the incentive to remedy to problem or adopt the promoted measures: Monetary incentives, which sometimes accompany soil conservation projects, have rarely yielded the desired effect, particularly in terms of long-term maintenance of structures and thus it is clear that incentives should be seen in a wider, culturally-specific context. There is usually sufficient incentive to invest in the land, for example, where land users have control over their own resources and lives. Most notable factors affecting incentive might be the security of tenure (this may take the form of land titles and privatization but it has been shown that cultural institutions usually serve the same purpose, Ostrom, 1990). Other factors are important, such as the relative priority accorded to land productivity maintenance (over, for example, off-farm activities that may yield higher returns to labor), as the incentive to invest in land is influenced in part, by the structure of multiple objectives of farmers as they pursue their livelihood strategies. Disincentives may include feelings of exploitation, such as through extraction of surplus, fluctuating prices, and powerlessness, such as may result from imposed conservation measures. Land quality may also be an important factor affecting the incentive to improve land (with better land tending to receive more investment). Furthermore, Mazzucato and Nie- 
meijer (2000) have recently demonstrated that soil and water conservation technologies were found to be more attractive if they maintained social networks. This cultural factor strongly mediated people's incentives to adopt introduced measures.

(d) They have the capability to remedy the problem: Capability can be seen as a function of available resources (conservation or land improvement often require additional land, labor or capital) and the social relations determining access and control (institutional and household). ${ }^{2}$ For example, the capability to manage common property resources without degradation implies an effective system of social organization where mutually agreed upon rules or policies are developed and adhered to. At an individual or household level, capability implies the power to make decisions and effect action. The farmer's level of access to resources and the demands placed on these resources by conservation technologies plays a critical role in the acceptability (or appropriateness) of the various technologies. If land is a limiting factor to production then practices that reduce the land area are unlikely to be embraced; if labor is limited then the gender division of labor and the timing of the various activities become critical to the adoption of technologies and if capital is limiting then any conservation measure requiring specialized equipment is unlikely to be acceptable (Stocking, 1993). ${ }^{3}$

All aspects of this analytical framework have been recognized by other authors ${ }^{4}$ and are inherent in meta-narratives of degradation (e.g., the neo-Marxist stresses access to resources, emphasizing capability as the key constraint). It is the contention here however, that the criteria have not been used together as a holistic framework for understanding farmer rationale and links with wider structural forces (that is, how factors become causes). In the case of adoption behavior models (of soil conservation technologies), one of the reasons for their lack of success in understanding farmer behavior may be their narrow focus on a limited range of variables. For example, only very recently has it been noted in adoption behavior research (by Mbaga-Smgalawe \& Folmer, 2000, p. 333) that a perception of the soil erosion problem is not a sufficient condition for using effective soil and water conservation measures; those who perceive but do not adopt may be unwilling (i.e., lack incentive) or unable (i.e., lack capability) to do so.

Finally, it is worth mentioning that the framework is consistent with the popularly emerging "sustainable livelihoods" approach. Birch-Thomsen, Frederiksen, and Sano (2001) identify three dimensions inherent in the livelihoods approach, each encompassed by this framework: how wider socioeconomic and socio-political change relates to local change; emphasis on the importance of socio-differentiation and agency in determining outcomes of local change and the importance lent to both physical and social resources employed in shaping livelihood strategies. The framework is summarized in Figure 1 and the valuable insights that can be gained through its application are illustrated in the two case studies below.

\section{METHODOLOGY}

Semi-structured interviews were conducted with 60 farmers in Tanzania and 40 in Thailand. In addition, a range of participatory rural appraisal (PRA) techniques were employed in

Recursively reworks

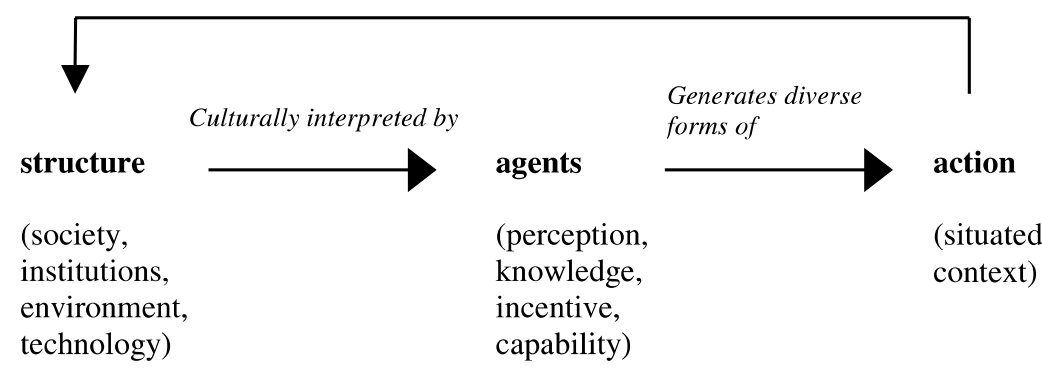

Figure 1. Analytical framework. 
Tanzania, such as matrix ranking, transect walks and wealth ranking. In Thailand some secondary data, collected by the Department of Land Development, is also used. In Tanzania, the whole of the Mgeta area was surveyed (including the villages of Langali, Pinde and Nyandira), whereas in Thailand, research was concentrated in and around Huai Cha Khan village. Data were collected over a period of a year in Tanzania in 1994 and three months in Thailand in 1997.

\section{CASE STUDY ONE: LAND DEGRADATION IN THE ULUGURU MOUNTAINS, TANZANIA}

The Uluguru Mountains lie approximately $200 \mathrm{~km}$ directly west of Dar-es-Salaam. They rise to an altitude of $2,600 \mathrm{~m}$ and are composed of steeply dissected slopes (averaging around $40^{\circ}$ ). Colonial administrators in the 1940 s believed the area to be suffering from land degradation as a result of population pressure (see Jones, 1996a for a more detailed discussion). But, since the failed attempts to implement bench terraces in the early 1950 s, little research had been undertaken in the area and population densities continue to rise (currently standing at about 160 persons $/ \mathrm{km}^{2}$ ). The study focuses around the area of Mgeta, inhabited by the Luguru, who almost universally grow maize and beans as their primary staple crops during the rainy season. A system of ladder terracing has developed which incorporates crop residues back into the system. While this does minimize erosion and landsliding and maximize nutrient recycling, it involves pulling down soil from upslope to bury the residues and therefore is gradually resulting in shallow and less fertile soils on the upper slopes (Jones, 2000). Temperate vegetables are grown during the dry season on wider flatter terraces with access to irrigation water that are located nearer the homesteads. These are reconverted to ladder terraces for rainy season cultivation of maize and beans. ${ }^{5}$ The soils in the area have been classified as "not differentiated ferrisols" (D'Hoore, 1964), that is, a transitional group evolving under a hot and humid climate whose development is retarded compared to neighboring soils (because of lower temperatures). Their resultant higher exchangeable base content, better structure and higher fertility would increase their resistance to erosion.
In Mgeta, in agricultural work, men and women work the same hours on the same tasks on the same fields, (although women undertake $80 \%$ of domestic tasks in addition, Mtenga, 1993). This relative absence of agricultural division of labor leads to rather undifferentiated interests, knowledge and perceptions, and most constraints and incentives affect men and women equally. In terms of interhousehold differentiation, while social mechanisms exist to minimize wealth differences (see Jones, 1996b), important differences exist between those households which are in a position to hire labor and those which are forced to sell labor, as this case study reveals. ${ }^{6}$

\section{(a) Perception}

It has been widely assumed by outsiders that the Luguru do not consider erosion to be a problem because they resisted the conservation measures promoted by the colonial administrators. In Kiluguru, the local language, the term soil erosion, encompasses mass movements such as landslides as well as soil erosion. Thus a distinction is made between "large" and "small" erosion. While "large" erosion is universally considered to be a problem (although landslide scars are rehabilitated in around only 3-4 years), "small" soil erosion (sheetwash and rilling) is not consider to be a particular problem. It is likely that the ladder terraces are effective in curbing it (Temple \& Murray-Rust, 1972). It was however, widely perceived that the maize fields, particularly on sloping land, were becoming exhausted and it was often reported that "the land is tired." 7 In terms of yields, $47.5 \%$ of people felt that they were declining and $95 \%$ of these people attributed the decline to erosion and exhaustion. Only $2.5 \%$ of people felt yields were increasing (solely because of increased artificial fertilizer use) and $45 \%$ of people felt yields varied annually depending on rainfall and fertilizer inputs primarily (the remaining $5 \%$ of people did not know). Given the widespread perception that land degradation is a problem in this area, this criterion cannot be considered to be a constraint to the improvement of soil.

\section{(b) Knowledge}

When asked, farmers knew on average 3.7 methods to improve soil fertility and 2.2 methods to reduce erosion. These included a wide range of techniques for improving the 
land. But these figures are not fully representative of people's knowledge as many people did not mention techniques which they practiced (e.g., ladder terracing) yet they could explain the benefits when asked directly about them. Pig manure and artificial fertilizer were identified as most beneficial for fertility improvement. These both represent a net import of nutrients into the area (pigs need to be fed on maize bran to be profitable and this has to be brought into the area). The remaining techniques such as mulching, burning, intercropping, agroforestry and fallowing primarily represent maximizing nutrient recycling within the system. Trees were most preferred for erosion reduction as their roots reduced the incidence of landsliding.

People employed on average 1.5 fewer fertility improving measures and 0.4 fewer erosion prevention measures than they knew about and thus a lack of knowledge of techniques cannot be a limiting factor contributing to soil improvement. All farmers said that they would keep pigs and manure their fields if they were financially able to do so.

\section{(c) Incentive}

Because of the strong ideology of self-reliance which places food crop production at the fore and a system of inheritance that ensures security of tenure, incentives to improve land are strong and long-term tenurial land rights in Mgeta are secure.

Returns to labor affect incentives significantly in this area as greater returns may be obtained from off-farm employment than investment in agriculture. Seasonal and semipermanent out-migration is an important livelihood strategy, reflected in the sex ratios for the 15-44 year age group of 0.78 in $1988 .^{8}$ This factor however is strongly mediated by the fact that the Luguru are very attached to the mountains, as their ancestral home, for the cool climate and low incidence of malaria (Brain, 1980). Were it not for this, migration might be expected to be higher. Thus it is mostly men who do not have sufficient access to land in this matrilineal society (usually single males or married men from poor clans) who tend to migrate and seek off-farm employment.

Land quality is another important variable affecting incentives in this area. Barbier (1990, p. 53) notes that "the more productive or profitable the land use the more farmers will be willing to maintain and invest in better land management and erosion control practices." In Mgeta, the relatively flat, irrigable land suitable for vegetable production generates greater returns to labor and capital, and therefore a stronger incentive to invest. Thus it receives much more attention than steeply sloping fields given to maize and beans. Most maize fields benefit only from nutrient recycling (reincorporation of crop residues), with infrequent additions of artificial fertilizer. Even wealthier farmers do not invest heavily in improving the productivity of their steeply sloping maize fields. This is because maize can be purchased more cheaply on the market than it costs to cultivate. Returns to investment therefore rarely warrant the use of optimal artificial fertilizer applications or pig manure (with the added cost of being heavy to carry to more distant fields), so those with money to invest direct it elsewhere. Yet they continue to cultivate maize without making investments in the land that it needs, because of the persistence of a strong self-sufficiency ideology in this area, inherited from the time that Nyerere was in power. Poorer households prefer to grow maize because of low access to cash incomes that would enable them to purchase it.

Thus, distance from homesteads and low returns for maize production are two factors generating relatively low incentives to improve poor quality land, despite secure tenure. Incentives to invest in land suitable for vegetable production, however, are strong.

\section{(d) Capability}

\section{(i) Land}

Land shortage was the main reason that people cited for being unable to implement erosion prevention methods $(43 \%)$ as trees and terraces both absorb land and trees further shade crops. It was also cited as a constraint to improving fertility by $26 \%$ of people (referring to the desire for longer and more frequent fallows). Thus population pressure, (as it lowers per capita land availability), could be regarded as a factor contributing to degradation in Mgeta but other factors affect whether this results in intensification with soil improvement or degradation.

\section{(ii) Labor}

Local people will not convert their ladder terraces into more permanent terraces because they say they would be too labor intensive to maintain (it would involve digging residues into 
the soil twice annually rather than pulling soil downslope to bury them). With significant rates of out-migration, labor can hardly be said to be a constraining variable to land improvement - thus returns to labor, as outlined above, must be regarded as more significant.

\section{(iii) Capital}

Poverty is reported to be increasing in the area as subsidies on artificial fertilizers have been removed through liberalization and competition in vegetable production increases. While it was found that there is relatively little wealth differentiation in Mgeta due to "internal" (cultural) redistribution mechanisms (Jones, 1996b), that which does exist clearly indicates the role of poverty in causing land degradation. A financial constraint was the main reason cited for not being able to improve the fertility of the land (noted by $67 \%$ of people). Pigs and artificial fertilizer, ranked most highly in terms of their capacity to improve the soil are also the most expensive measures. It does not follow however that is the poorest who degrade the land most (or that it is the wealthiest who invest most in the land, as shown above). What actually happens in Mgeta is that the poorest are often eager to sell their labor, as they are desperate for cash income to buy necessities. In so doing they are rarely able to cultivate all their own fields and so these fields benefit from more regular fallowing than those belonging to wealthier people. Furthermore, poorer households sometimes have access to land suitable for vegetable cultivation. Vegetable production requires much investment to be profitable (e.g., pig manure), which can rarely be afforded. Therefore this land is frequently rented to wealthier farmers and benefits from the additional nutrients that vegetable production necessitates.

\section{(e) Summary: causes of land degradation in the Uluguru Mountains}

The use of this framework in an actor-oriented context has illustrated how it is possible to avoid a "shopping list" of causes by examining the webs of interactions between different variables. The diversity of outcomes in terms of land management and soil quality can be explained by grounding concepts of land management in the everyday lives of men and women. A complex picture emerges as the various responses to the same structural conditions are explored. A financial constraint (capability) emerges as a primary cause of land degradation on the more productive soils, although poorer people's strategies include renting out fields, hiring labor, and growing less demanding crops (such as cassava) help to avoid land degradation. On the low-fertility land, poor returns and distance from homesteads (incentive) are primary reasons for lack of investment. Here the reflexive relationship between structure ("external") and action ("internal") is evident. As fewer resources are invested in the more distant soils, they become poorer in quality, which further lowers the incentive to invest in them. This may be responded to by a change in action to; (i) fallowing, although this is made difficult by higher population densities, (ii) increased inputs, which is difficult due to increasing poverty, (iii) out-migration, which is not a preferred option but is practiced by many single, landless males or those from poor clans with low access to land or (iv) land exhaustion, which is an outcome on many farmers' sloping maize fields.

\section{CASE STUDY TWO: SOIL CONSERVATION IN THE HIGHLANDS OF NORTHERN THAILAND}

The second case study is in and around Huai Cha Khan village, in the Chiang Dao District of Chiang Mai Province, where population densities stand around 26 persons $/ \mathrm{km}^{2}$. The area is inhabited by the Lahu hilltribe, who traditionally were "pioneer" shifting cultivators, cultivating the land for 3-4 years before moving to new land (TRI, 1970). The Lahu are one of the ethnic groups of shifting cultivators who have historically engaged in opium production. Thus government interest in these areas emerged out of strategic and security concerns, but have been overlain by sociopolitical (opium production) and environmental (deforestation and flooding) concerns. Traditionally, and prior to the project, in addition to opium, farmers grew rice and corn as their main staple crops and melons, pumpkins, potatoes, bananas and chillies as their second crops (TRI, 1970). ${ }^{9}$

The slopes in the area range from $12 \%$ to $35 \%$ (DLD, 1995). Rainfall is about $1,400 \mathrm{~mm}$ falling predominantly between May and October (DLD, 1995). Both sedimentary and metamorphic rocks form the parent material (limestone and black and gray shale) and soils have been classified as paleustults and haplustalfs (DLD, 
1995). They are deep, moderately well drained soils, of dark brown to dark reddish brown colour and clay loam to silty clay loam texture.

A soil conservation project was implemented in the area in 1989, managed by the Department for Land Development (DLD) and forming part of the International Board for Soil Research and Management's (IBSRAM) network on the management of sloping lands for sustainable agriculture in Asia (ASIALANDS). The aims of the project are to encourage shifting cultivators to settle by maintaining soil fertility without high cost external inputs and to find viable alternatives to the opium cash crop. Vegetative technologies are being promoted to this end. When fieldwork was undertaken, the project was in its third phase, which involves training farmers and further promoting the technology (alley cropping with leucena and pigeon pea) that had been validated on-station (phase I) and onfarm (phase II). DLD is also encouraging the planting of fruit trees (particularly mango) and the cultivation of two annual crops per year for soil improvement and protection, the second being a leguminous relay cover crop.

Research by the Anacksamphant, Boonchee, Inthapan, Teajajai, and Sajjapongse (1995) showed that erosion was reduced under the technology promoted compared with the farmers' practice, on average, by 20 times during 1992-94 inclusive, thus it may be regarded as physically appropriate for the purpose of combating erosion. As this case study reveals, however, soil erosion is not always the most significant concern for farmers. Furthermore, agroforestry technologies have been reported to have delayed returns to labor and as such, may not always be appropriate to farmers' who do not have reserves of capital. The aim of this study then, was to use the framework to identify potential constraints that farmers face in the adoption of recently introduced soil and water conservation technologies in northern Thailand.

Among the Lahu, women have relatively strong "fall-back positions" in that they retain their property in the case of divorce and there are no major obstacles to remarriage (TRI, 1970) yet this seems not to affect their influence in decision-making. Women interviewed said that they would always follow their husbands' decision and they would not create problems if they disagreed with a decision. Women have no land solely for their own use in this village and husband and wife work on all land together. In addition, TRI (1970, p. 383) note that "no dominant role is assigned to either sex and the work is shared equally between them." This would indicate that in the case of the Lahu, as in the Tanzanian case study, agricultural interests would not be strongly differentiated. Consequently, the DLD's focus on male heads of household for implementing soil conservation measures may not be a significant impediment to the adoption of soil conservation technologies.

In terms of interhousehold differentiation, there has been a gradual erosion over the last 50 years of land ownership as an indicator of wealth and class with the profound reorientation towards nonfarm income generation (Rigg \& Nattapoolwat, 2001). Rigg and Nattapoolwat (2001) believe that education level is likely to be a major differentiating factor at the beginning of the 21 st century as it has become the key determinant of the nonfarm opportunities open to people in rural Thailand. In the case study area household income ranged from 11,000 to 30,000 bhat per year in 1995 , and on average $37 \%$ of this came from off-farm sources. ${ }^{10}$

\section{(a) Perception}

When asked directly, $56 \%$ of people agreed that erosion was a problem, yet it was not mentioned at all when people were asked what soil problems existed. Indeed scientific assessments of erosion at the experimental site in Chiang Dao suggest that it may not be pronounced (Paningbatan, 1995). At Chiang Dao measured erosion losses were below the specified tolerance limit of $10 \mathrm{t} / \mathrm{ha} / \mathrm{year}$ even with the farmers' practice. This has been attributed to cohesive illite-halloysite clays, a high fine sand fraction and organic matter content, making the soils not particularly susceptible to erosion (Paningbatan, 1995; Anacksamphant et al., 1995).

Fifty-three percent of farmers did note, when asked about soil problems, that poor fertility was a problem. Similarly, when asked what problems were encountered in food production, only $20 \%$ of farmers noted that soil fertility was a problem compared with $71 \%$ who noted weed encroachment. Bourne (1992), in his evaluation of the Thai-German Highland Development Programme (TGHDP) also found this to be the case. Their initial assumption that high soil erosion and loss of fertility were the main reasons why farmers had to practice shifting 
cultivation had been invalid. Rather, people cleared new areas to avoid "the weed problem." Farmers withdrew from the TGHDP because the 3-4 year old rice plots under their conservation measures required weeding 3-5 times a year compared with the 1-2 times a year on younger traditional plots.

Clearly if DLD's measures are to be adopted, they must not increase weed growth and if weeds can be suppressed then measures are more likely to be adopted. DLD's measures, in fact, are aimed at all three of these problems. First, the hedgerows act as a physical barrier against soil loss and over time form a natural terrace, thus also reducing slope steepness. Second, the leguminous crops and the use of green manure from the hedgerow, improve the fertility of the soil. Third, the use of crop residues as a mulch and the cultivation of two crops per season act to reduce weed growth.

\section{(b) Knowledge}

Walker (1975) found that the Lahu use at least 61 species as indicators of the suitability of the soil for cultivation. This is clearly a type of functional knowledge that has developed to enable the Lahu to effectively identify new land. Perhaps not surprisingly though, during interviewing farmers said that they did not know of any methods to improve the soil and they did not practice any conservation techniques. The effects of population pressure and commercial deforestation have only become obvious in recent years and Huai Cha Khan settlement has only existed for about 30 years (the average length of residence of the interviewed farmers being only 14.5 years). This has given them relatively little time to experiment to develop productive and sustainable systems in the face of land scarcity.

DLD staff have been conscious not to introduce overcomplicated measures which may alienate or confuse farmers and they have taken much care to explain the value of their technologies and ensure proper implementation of the measures. They are however, introducing radically new systems and species and have overlooked successful indigenous practices employed by other hilltribe groups. For example, the Karen, the largest ethnic minority in northern Thailand, are reported to have practiced a very stable form of rotational swidden agriculture, that has enabled them to reside in the same village territory for two centuries (Rashid, 1975). Their investments and practices include: leaving belts of trees which serve as seed reservoirs, allowing a long fallow period between successive uses of upland fields, building terraces, and planting orchards of fruitbearing trees such as mango, jackfruit and coconut (Hinton, 1967). ${ }^{11}$ The adaptive strategies of the Karen's rotational system are in danger of being lost due to increasing population pressure (Rashid, 1975). Indigenous practices could be improved upon, to provide a more acceptable foundation for Lahu agriculture than the radically different alley cropping technologies promoted by DLD, which evolved elsewhere in Asia.

\section{(c) Incentive}

Alternative investments for both labor and capital need to be understood to assess the priority accorded to agriculture and soil conservation. There is likely to be a strong incentive to seek off farm employment in favour of an agricultural livelihood as incomes from nonagricultural activities have increased from 6.6 times higher in 1977 to 9.1 times higher in 1987 (DLD, 1995). This in turn may result in insufficient labor to invest in the adoption or maintenance of conservation measures. In the study area only $15 \%$ of household income was attained from wage labor, thus it is unlikely to amount to a significant drain on labor. The revenue generated may actually improve the capability to invest in conservation measures (see below).

It is critical that farmers feel in control of their lives, hence projects that dictate to farmers what they should practice will be unlikely to provide any incentive for co-operation. There are accounts of strong reactions and resistance to coercive policies in Thailand. Sombatpanit, Sangsingkeo, Palasuwan, and Saengvichien (1993) and Onchan (1990) found that farmers had the belief that soil conservation structures were constructed and owned by the government and were a form of aid. Thus they saw conservation projects as the government's responsibility and when structures become damaged they should be repaired by the government. DLD staff have taken the expert and educator role and an approach which strengthened farmers' involvement (e.g., in technology design, evaluation and experimentation) and innovation capacity may further encourage adoption and maintenance of conservation measures. Rigg (1991) has argued, however, somewhat controversially perhaps, that because 
authority structures in Thailand are so strong, working through authority channels and influential people such as village heads as the DLD has done (as opposed to aiming for "capacitybuilding" or "empowerment"), is the best way of ensuring effective project implementation and adoption of conservation measures.

As noted earlier, security of tenure is widely recognized as an important prerequisite to sustainable land management. The current system of land tenure in Thailand is complex, as it is in transition between traditional and modern legal systems and has been for some time (Ganjanapan, 1994). This picture is complicated further in the highlands as $40 \%$ of the forested land in Thailand is officially designated as forest reserve and is inhabited by more than one million farming families with no legal documents (Ganjanapan, 1994). Even on private land, $30 \%$ of households do not have title deeds (Ganjanapan, 1994). This leads some to suggest that there is a lack of a "sense of belonging" and little incentive to practice anything other than shifting cultivation (Raintree, 1986; quoted by Ruaysoongnern \& Patanothai, 1991). Added to this, the Lahu feel no enduring ties that bind their community to a particular place (Walker, 1975). Unlike other tribal groups, the Lahu village society generally lacks clan, lineage or other corporate groups based on descent principles (Walker, 1975). However, Ganjanapan (1994) argues that most villagers are confident of the security of their land tenure based on traditional principles. Hirsch (1990, p. 169) also states that "despite the de jure insecurity of forest reserve status, most farmers regard it as their own in much the same way as do those farmers with legal title." This assertion is supported by Harper and El-Swaify's (1988) findings in northern Thailand that only $4 \%$ of people gave insecure land tenure as a reason for not adopting other conservation measures. With $95 \%$ of the land in the project area classified as "owned" (the other 5\% rented, DLD, 1995) insecurity of tenure is unlikely to significantly affect incentives to improve land.

While the Karen regard their land as a scarce resource, the Lahu historically regard the land as an unlimited resource and have traditionally worked it with the assumption that they will be doing so in a given area for a strictly limited time (Rashid, 1975). This assumption appears however to be changing as land pressures increases. All of the farmers interviewed intend to remain in the area (over three-quarters because they do not feel there is anywhere else for them to go) and thus gain a livelihood from the same land. This suggests that they would have some interest in practices generating stable yields in the longterm.

\section{(d) Capability}

\section{(i) Capital}

The proportion of income spent on food is often used as an indicator of poverty. Expenditure data collected by the DLD show that a very high proportion of income in all cases is used to buy food, and rice in particular (83$97 \%$ ). This indicates a very high level of poverty among the population and suggests that farmers would be incapable of adopting any soil conservation technology that requires large investments of capital.

There is considerable evidence, however, both from the farmers and from data collected on experimental plots, to suggest that the costs of the conservation technology are no greater than costs presently borne by farmers. Costs of materials were found on the experimental plots to be lower over a five-year period (1989-93) for the promoted alley cropping system than the farmers' practice. The major expenditure in both cases was the kidney bean seeds, for which the farmers' practice required over twice as many, because of the much more dense crop spacing practiced. In addition, in a ranking exercise of eight soil improvement practices undertaken by the author $(N=30)$, farmers consistently placed artificial fertilizer as the most expensive method for improving soil fertility (ranked at an average of 1.1 , where 1 is the most expensive), yet many farmers use it (it was also ranked as the most effective means by which fertility may be improved). Hedgerows were ranked less expensive (3.7) than manuring (3.4), and composting (3.2) while agroforestry was ranked second highest (2.4). As farmers can afford to buy artificial fertilizer, lack of capital is unlikely to be the reason for nonadoption of hedgerows.

\section{(ii) Labor}

Labor costs (inputs) for the alley cropping treatment on the experimental plot were measured to be slightly lower than the farmers' practice (at 577 and 613 US\$/ha respectively, DLD, 1995). It is likely however, that returns to labor are more important. Over a three-year period on the experimental plots it was found 
that the alley cropping system had very similar returns to the farmers' practice (at 173 and 178 US\$/ha respectively, DLD, 1995). The alley cropping system would yield higher incomes in the longer term as the fruit trees matured.

In terms of the ranking exercise, hedgerows ranked at 2.6, were considered to be more labor intensive than composting (2.9), and burning was considered to be more labor intensive than both (2.4). Given that burning is part of the "traditional" shifting cultivation practice and has higher labor demands than the promoted technology (hedgerows), labor availability is unlikely to be a significant constraint to adoption. Furthermore the majority of farmers $(85 \%)$ felt that overall the traditional and introduced practices consumed a similar amount of labor.

\section{(iii) Land}

The conservation technologies promoted by DLD are land-demanding as land is taken out of production for the hedgerows. Over time it is anticipated that higher yields on the remaining land would compensate for the area taken out of production. This has not, however, been evident from data collected on the experimental plots over a five-year period. Corn yields (returns to land) were lower at $2.93 \mathrm{t} / \mathrm{ha}$ compared with $3.24 \mathrm{t} / \mathrm{ha}$ on the farmers' practice over the same period (there is no clear trend over time in terms of yields declining on farmers' practice and increasing with the conservation practice as might be expected). Bean yields were slightly higher at 0.62 and $0.5 \mathrm{t} /$ ha respectively. ${ }^{12}$ One farmer interviewed said that he would not be able to adopt the measures as he did not have enough land but most others considered that yields were higher under the conservation technologies.

\section{(e) Summary: constraints to the adoption of soil conservation measures in}

\section{Huai Cha Khan}

Farmers do perceive erosion to be a problem (although not a very significant one compared with soil fertility decline and weed encroachment), and although they may not have secure title deeds to their land, they consider it to be their own and intend to use it in the long term, thus perception of a problem and incentive to invest in the land do exist. While the somewhat top-down approach of DLD may have stifled incentives in other parts of the world, it may not present a significant constraint in Thailand.
A responsiveness to authority structures furthermore may enable DLD to effectively promote new and alien technologies, whereas elsewhere a greater interest may have been obtained through the development of indigenous practices. The greatest constraint may be that, despite the slightly lower cost and labor requirements of the promoted technologies, there is little evidence for significantly improved yields. One farmer who was interviewed explained "Why should I be interested in this project? Look, you can see the yields are no better." It is probable that soil erosion has not yet caused significant decline in yields in farmers' own practice. Although the conservation technology has multiple functions including the improvement of soil fertility and the suppression of weeds, if farmers are going to change radically the practices that they are used to, the benefits in terms of their stated primary objective-yield maximization-may need to be much more apparent. But, as most farmers did consider that yields were slightly higher, it appears that none of the four factors were significantly limiting, which bodes well for the future adoption of this technology.

\section{COMPARISONS BETWEEN CASE STUDIES}

It is not valid to draw any broad generalizations from only two case studies, nonetheless comparative analysis can yield useful insights. In both places, there was not a strong perception that erosion was a problem and indeed erosion rates in each place were unlikely to have been high. In Mgeta, Temple and MurrayRust (1972) suggested that ladder terraces are effective in curbing erosion and in Thailand, Paningbatan (1995) had measured rates and suggested they were within tolerable limits. In contrast, fertility decline in both places was considered to be a more significant problem by most people, despite compensatory measures taken in Tanzania. Thus, measures to improve fertility rather than reduce erosion are more likely to be adopted or developed in both places. In Thailand, measures which give higher yields because of weed growth suppression would be even more attractive.

All farmers in the Tanzania case study knew of more measures to halt fertility decline than they were able to employ, thus a lack of knowledge could not be regarded as a key 
constraint to soil improvement. In Thailand, in contrast, a relative lack of familiarity of the agricultural environment and appropriate conservation measures could, in the short-term, be regarded as a constraint, but it is this "knowledge gap" that the DLD is aiming to plug with its technologies.

In terms of incentive to invest, in both places, agricultural production and soil conservation may be competing, to some extent, with the desire to earn off-farm income. Paradoxically, this additional income may be instrumental in facilitating the investment in agriculture needed for it to be profitable in Tanzania. In contrast, in northern Thailand, if the suggestions of Rigg and Nattapoolwat (2001) are correct, agriculture can be expected to decline further as young people prefer to engage in more nonfarm work. Low returns to investment in poorer quality land in the Uluguru Mountains is one of the most significant factors affecting investment and there is every indication that this is also significant in Thailand.

Poverty is a significant constraint to soil improvement in the Uluguru Mountains. Poverty is also extremely prevalent in northern Thailand, but the measures promoted by DLD are no more demanding in terms of capital than farmers' own practice. Were measures to be developed in the Uluguru Mountains that improved soil fertility without adding financial burden or consuming land, it is likely that they would be adopted. The DLD's measures in
Thailand appear to do just this, but do not seem to result in significantly higher yields. Thus it may not be that until farmers' yields decline significantly that they will be universally adopted.

\section{CONCLUSION}

This paper has presented a framework to show how factors affecting degradation become causes. It focused on the decision-making context of the land user as a medium for explanation rather than utilizing a grand theoretical perspective. Such a focus may be of value in explaining other forms of environmental degradation such as deforestation. Other authors (e.g., Barraclough \& Ghimire, 1996; Scoones, 1997) have called for a move away from simplistic and deterministic explanations of environmental degradation. It is hoped that this paper offers an approach capable of explaining spatial heterogeneity, and generating embedded and context-specific studies, to deepen understandings and enable the formulation of more appropriate policy. Furthermore, when applied to soil conservation technology adoption, by examining in detail the range of social and cultural factors that may explain farmer behaviour, it moves away from excessive reliance on economic determinants and may serve as a greater predictor of success than many adoption models.

\section{NOTES}

1. The framework assumes that the measures being introduced are physically appropriate, i.e., that they do actually improve the soil. But, this is only part of the picture. The "physical" is embedded within the "social" and the notion of appropriateness relates also to the nature of farmers' priorities (see "incentive" below) and resource endowment (see "capability" below).

2. The idea of capability here, resembles the notion of environmental endowments and entitlements discussed by Leach, Mearns, and Scoones (1997). It becomes clear then, that the notion of environmental entitlements alone, being only one of the four criteria, is insufficient to explain environmental degradation.

3. The four criteria listed here are not independent of each other nor are they static.
4. For example, Cramb, Garcia, Gerrits, and Saguiguit (2000, p. 917) critically evaluate three "communitybased sustainable development projects" in the uplands of the Philippines. Their first project, in Palawan Province, aimed to promote agroecologically sound farming technologies (particularly bench terracing and contour ploughing) but farmers suffered from the following problems: "they did not know how to establish or maintain the structures" (knowledge), distance from the headquarters made it more difficult (incentive and capability), a long time before the realization of benefits (incentive and capability), trees prevented burning and caused shading (culturally and physically inappropriate), "they did not see soil erosion as a major problem" (perception), "technologies were labor (and skill) intensive while labor was their major limiting factor" (capability) and adoption meant incurring a high social and economic cost (incentive). 
5. Tanzania is known historically for its socialist development agenda, following the Arusha Declaration in 1967 under Nyerere. The strong centrally planned economy, where government control was greater than in any other country in sub-Saharan Africa, "agricultural producers were implicitly contract farmers to the government" (Temu \& Due, 2000). Since 1986, the government has been undertaking economic reforms supported by the International Monetary Fund (IMF) and the World Bank, but because of the severe suppression of the private sector that preceded the reforms, Tanzania had a very different starting point and economic liberalization structural adjustment processes have been particularly challenging in this context (Temu \& Due, 2000). Temu and Due (2000) found that while there has been an increase in the participation of the private sector in the economy and achievements in the macroeconomic context, there has been an apparent lack of tangible benefits to many of the poorest sections of Tanzanian society.

6. A matrix ranking exercise revealed that those who owned a shop, could afford to buy fertilizers, kept pigs or had family in town were considered to be the wealthiest - revealing the importance of being able to invest in the land to generate income.

7. This was confirmed by soil analysis, which revealed significant nutrient decline on the maize fields relative to virgin forest soils. Long-cultivated vegetable soils in contrast fared similarly to recently cultivated maize soils, indicating significant inputs of organic and artificial fertilizers to compensate for nutrient losses (see Jones, 2000 for more details).

8. The sex ratio for Tanzania as a whole in the 15-64 age group, by comparison, was 0.94 in the same year.

9. Agriculture in Thailand has been dominated traditionally by small family farms growing rice (Hayami, 2001). But, the commercialization of agriculture was already apparent in the 19th century and this was accelerated in northern Thailand upon the completion of the Chiang Mai-Bangkok railway (Rigg \& Nattapoolwat, 2001). Unlike in Tanzania, the government intervened little in the activities of private traders - who were supported by major public expenditure in infrastructure. Thailand became the world's largest rice exporter, and since the export-oriented strategy was adopted in the 1970s there has been a "remarkable diversification of agricultural resources to new export crops" (Hayami, 2001). The World Bank recognized Thailand as the fastest growing economy in the world during 1985-1994 (Goss \& Burch, 2001). Yet during the latter decades of the 20th century, agriculture has been barely able to meet the needs of the average family due to declining land resources, stagnant prices for farm produce and a rise in demands on family income (Rigg \& Nattapoolwat, 2001). Thus nonfarm work has become critical for both augmenting and stabilizing rural livelihoods. Because of the attention given to the industrial sector which has penetrated into rural areas, farmers are highly mobile and circulate between factory and field. Rigg and Nattapoolwat (2001) found little evidence to suggest that the financial crisis of 1997 substantially altered individuals' livelihood strategies and point out that, ironically, it was those households most deeply embedded within the global economy that survived the economic recession best.

10. Source: Raw secondary data provided by the DLD $(n=20)$.

11. Others include preventing uncontrolled fires, carefully felling swiddens to ensure quick regeneration, preserving trees inside the swidden itself, and avoiding hoeing steep slopes to preserve soil structure and resistance to erosion (Rashid, 1975).

12. Unfortunately data regarding rice yields, farmers' most important staple crop, were not gathered by DLD.

\section{REFERENCES}

Anacksamphant, C., Boonchee, S., Inthapan, P., Teajajai, U., \& Sajjapongse, A. (1995). The management of sloping lands for sustainable agriculture in northern Thailand. In A. Sajjapongse, \& Elliot, C. R. (Eds.) ASIALANDS: The Management of Sloping Lands for Sustainable Agriculture in Asia (Phase 2, 1992-94), Network Document No. 12, Bangkok, Thailand.

Barbier, E. (1990). Natural resource degradation: policy, economics and management. In J. T. Winpenny (Ed.), Development research: the environmental challenge. London: ODI.
Barraclough, S. L., \& Ghimire, K. B. (1996). Deforestation in Tanzania: beyond simplistic generalisations. The Ecologist, 26(3), 104-109.

Birch-Thomsen, T., Frederiksen, P., \& Sano, H.-O. (2001). A livelihood perspective on natural resources management and environmental change in semiarid Tanzania. Economic Geography, 77(1), 41-66.

Boserup, E. (1965). The conditions of agricultural growth. London: Allen and Unwin.

Bourne, W. (1992). Nam lang impact survey, Thai-German Highland Development Programme, 
Internal Paper Number 165, Bangkok, Thailand.

Brain, J. L. (1980). The Uluguru land usage scheme: success and failure. Journal of Developing Areas, 14, 175-190.

Cramb, R. A., Garcia, J. N. N., Gerrits, R. V., \& Saguiguit, G. C. (2000). Conservation farming projects in the Philippine Uplands: rhetoric and reality. World Development, 28(5), 911-927.

D'Hoore, J. L. (1964). Soil map of Africa, Commission for Technical Co-operation in Africa, Inter-African Pedological Service Joint Project No. 11.

DLD (Department for Land Development) (1995). Socio-economic study of the farmers of the IBSRAM test and demonstration plot, Chiang Mai Site, Office of Land Development Region 6, Bangkok, Thailand.

Ganjanapan, A. (1994). The Northern Thailand tenure system: local custom versus national laws. Law and Society Review, 28(3), 609-622.

Goss, J., \& Burch, D. (2001). From agricultural modernisation to agri-food globalisation: the waning of national development in Thailand. Third World Quarterly, 22(6), 969-986.

Harper, D. E., \& El-Swaify, S. A. (1988). Sustainable agricultural development in Northern Thailand: conservation as a component of success in assistance projects. In W. C. Moldenhauer, \& N. W. Hudson (Eds.), Conservation Farming on Steep Lands. Ankeny IA: Soil and Water Conservation Society.

Hayami, Y. (2001). Ecology, history and development: a perspective from rural Southeast Asia. The World Bank Research Observer, 16(2), 169-198.

Hinton, P. (1967). Introduction. Tribesmen and peasants in North Thailand, Proceedings of the First Symposium of the Tribal Research Centre, Chiang Mai, Thailand.

Hirsch, P. (1990). Forests, forest reserve and forest land in Thailand. The Geographical Journal, 156(2), 166174.

Jones, S. J. (1996a). Degradation discourses in the Uluguru Mountains, Tanzania: Evolution and Influences. Journal of Rural Studies, 12(2), 187-199.

Jones, S. J. (1996b). Farming systems and nutrient flows: a study from the Uluguru Mountains, Tanzania. Geography, 353(81), 4289-4300.

Jones, S. J. (1999). From meta-narratives to flexible frameworks: an actor level analysis of land degradation in highland Tanzania. Global Environmental Change, 9, 211-219.

Jones, S. J. (2000). Intensification, degradation and soil improvement: utilising structuration theory for a differentiated analysis of population pressure outcomes in highland Tanzania. Singapore Journal of Tropical Geography, 21(2), 131-148.

Leach, M., Mearns, R., \& Scoones, I. (1997). Challenges to community-based sustainable development: dynamics, entitlements and institutions. IDS Bulletin, 28(4), 5-14.

Long, N. (1992). An actor-oriented paradigm. In N. Long, \& A. Long (Eds.), Battlefields of knowledge. London: Routledge.

Long, N., \& van der Ploeg, J. D. (1994). Heterogeneity, actor and structure: towards a reconstitution of the concept of structure. In D. Booth (Ed.), Rethinking social development: theory, research and practice. Harlow, Essex: Longman Scientific and Technical.

Mazzucato, V., \& Niemeijer, D. (2000). The cultural economy of soil and water conservation: market principles and social networks in Eastern Burkina Faso. Development and Change, 31, 831-855.

Mbaga-Smgalawe, Z., \& Folmer, H. (2000). Household adoption behavior of improved soil conservation: The case of the North Pare and West Usambara Mountains, Tanzania. Land Use Policy, 17, 321-336.

Mtenga, N. A. (1993). Gender roles in the domestic and farming systems of the Tchenzema Ward, Morogoro District, Tanzania, MSc Dissertation, Sokoine University of Agriculture, Morogoro, Tanzania.

Onchan, T. (1990). A land policy study, The Thailand Development Research Institute Foundation, Research Monograph No. 3, Bangkok, Thailand.

Ostberg, W. (1991). Land is coming up: burungee thoughts on soil erosion and soil formation. EDSU Working Paper No. 11, University of Stockholm, Sweden.

Ostrom, E. (1990). Governing the commons: the evolution of institutions for collective action. Cambridge: Cambridge University Press.

Paningbatan, E. (1995). The ASIALAND management of sloping lands network: Soil erosion under different soil conservation practices. International Workshop on Conservation Farming for Sloping Uplands in Southeast Asia: Challenges, Opportunities and Prospects, (pp. 109-126) IBSRAM Proceedings 14.

Pawluk, R. R., Sandor, J. A., \& Tabor, J. A. (1992). The role of indigenous soil knowledge in agricultural development. Journal of Soil and Water Conservation, 298-302.

Rashid, M. D. (1975). Karen swiddening techniques. A. R. Walker (Ed.), Farmers in the Hills: ethnographic notes on the upland people of North Thailand, School of Comparative Social Sciences, Universiti Sains, Malaysia.

Rigg, J. (1991). Grass-roots development in rural thailand: a lost cause? World Development, 19(2/3), 199-211.

Rigg, J., \& Nattapoolwat, S. (2001). Embracing the global in thailand: activism and pragmatism in and era of deagrarianisation. World Development, 29(6), 945-960.

Ruaysoongnern, S., \& Patanothai. (1991). Farmers' perceptions and the adoption of sustainable land management technologies-Thailand's experience. Evaluation for Sustainable Land Management in the Developing World, IBSRAM Proceedings, No. 12, Vol. 2.

Scoones, I. (1997). The dynamics of soil fertility change: historical perspectives on environmental transformation from Zimbabwe. The Geographical Journal, 163(2), 161-169.

Scoones, I., \& Thompson, J. (1994). Knowledge, power and agriculture: towards a theoretical understanding. In I. Scoones, \& J. Thompson (Eds.), Beyond farmer first (pp. 16-31). London: Intermediate Technology Publications Ltd., IIED.

Sombatpanit, S., Sangsingkeo, S., Palasuwan, N., Saengvichien, S. (1993). Soil conservation and farmers' 
acceptance in Thailand. In Acceptance of Soil and Water Conservation Strategies and Technologies, Topics in Applied Resource Management in the Tropics (pp. 307-340), DITSL (Deutsches Institut fur Tropische und Subtropische Landwirtschaft), Witzenhausen, Germany.

Stocking, M. (1993). Soil and water conservation for poor farmers: designing acceptable technologies for rainfed conditions in Eastern India. Topics in Applied Resource Management, 3, 291-305.

Temple, P. H., \& Murray-Rust, D. H. (1972). Sheet wash measurements on erosion plots at Mfumbwe, Eastern Uluguru Mountains, Tanzania. Geografiska Annaler, 54A(3-4), 195-202.

Temu, A. E., \& Due, J. M. (2000). The business environment in Tanzania after socialism: challenges of reforming banks, parastatals, taxation and the civil service. Journal of Modern African Studies, 38(4), 683-712.

TRI (Tribal Resources Institute) (1970). Lahu, Ethnographic Study Series: Minority Groups in Thailand, Tribal Research Institute, Chiang Mai University, Thailand.

Walker, A. R. (1975). The Lahu people: an introduction. In A. R. Walker (Ed.), Farmers in the hills: ethnographic notes on the Upland People of North Thailand. Malaysia: School of Comparative Social Sciences, Universiti Sains.

Whitesell, T. (1994). Some thoughts on the unresolved epistemological dilemmas confronting political ecology, Proceedings from the Political Ecology Workshop, Michigan state university, April. 